\title{
APRESENTAÇÃO
}

\section{LETRAMENTO E INTERCULTURALIDADE: DO EVENTO VERNACULAR AO EVENTO ESCOLAR}

\author{
Angela B. Kleiman ${ }^{1}$ \\ Cosme B. dos Santos ${ }^{2}$
}

Não é de praxe fazer uma apresentação dos artigos numa revista, mas também esta não é uma apresentação como dita a praxe, pela estrutura composicional, que não identifica autores nem respeita a ordem dos textos no sumário. Aqui, os últimos são os primeiros, pela primazia do tema - multiletramentos locais - e a importância de seu conhecimento para o planejamento de programas educacionais que visem inserir os alunos em práticas letradas ideológicas ${ }^{3}$. E os primeiros são agrupados mais para o final, porque todos os textos sobre letramento escolar incluídos no volume são ilustrativos de um processo de construção de base, tal como é a construção de práticas letradas que dão sustentação ao ensino para a diversidade e o multiculturalismo ${ }^{4}$, discutindo propostas de ensino a serem desenvolvidas pelo professor com a finalidade de reverter os processos

\footnotetext{
${ }^{1}$ Professora titular do Departamento de Linguística Aplicada do Instituto de Estudos da Linguagem (IEL/Unicamp); Pesquisadora CNPq. Doutora em Linguística. E-mail: akleiman@ mpc.com.br

2 Professor Pleno da Universidade do Estado da Bahia (UNEB, Campus III), Doutor em Linguística Aplicada. E-mail: cbsantos@uneb.br

${ }^{3}$ Esta categoria está associada à distinção que o precursor dos estudos do letramento, Brian Street (1984) faz entre o modelo autônomo de letramento (aquele que considera que a escrita por si só é capaz de mudar o indivíduo e, com ele, a sociedade, porque seria neutra e objetiva, independente da situação) e o modelo ideológico de letramento (aquele que reconhece que todas as práticas de letramento estão relacionadas à situação, à cultura e às estruturas de poder na sociedade). Posto que, de fato, todas as práticas letradas, inclusive as escolares, estão relacionadas à situação, à cultura e ao poder, existem termos mais precisos para caracterizar os letramentos acima referidos, tais como "vernáculos", ou "emergentes", ou "de resistência". Entretanto, optamos pelo uso do termo 'ideológico' para marcar nossa posição contra a deturpação do conceito de ideologia que está sendo realizada pela extrema direita brasileira por meio de usos da palavra em expressões que afetam diretamente a escola, como 'doutrinação ideológica' do movimento Escola sem Partido, ou ainda, como a apreciação pejorativa do conceito de 'ideologia de gênero", que o associa à desconstrução da família; à perversão, e assim contribui para a demonização e interdição do tratamento de temas relevantes sobre a sexualidade na instituição escolar.

${ }^{4} \mathrm{O}$ multiculturalismo nesse contexto nos remete ao intercultural, ou seja, não se reduz ao reconhecimento da diversidade cultural e ao respeito da diferença, mas implica um contexto de luta pelo reconhecimento de múltiplas existências de identidades culturais em situações de diálogos conflituosos, ou não, como, por exemplo, nas situações em que as tradições orais estão em interação com o saber e a escrita ensinada nos espaços escolares ou mesmo nos espaços de educação informal.
} 
de expulsão de populações vulneráveis pela escola (esta que, de antiga instituição da elite, passou hoje a ser instituição para salvaguardar os privilégios da elite, pela exclusão da maioria, pelo desprezo às produções do povo, pelo abandono dos mais pobres).

A compreensão do que as pessoas comuns fazem com a língua escrita, como a usam para atingir metas pessoais, ou do grupo a que pertencem - mulheres, poetas de cordel, rappers - , ou da comunidade em que vivem ou trabalham ou professam sua fé — escolas, terreiros de candomblé —, abre caminhos não trilhados pelas pesquisas sobre letramento no Brasil, no campo dos (multi)letramentos locais, ou vernáculos, apagados e até invisibilizados pelos letramentos oficiais.

Se, por um lado, não são encontrados no país sistemas de escrita alternativos aos da língua oficial, segundo as funções que a língua escrita desempenha, em parte devido à proibição de utilização da Língua Geral e à interdição, por séculos, de mulheres, negros, índios aos lugares em que se praticava a escrita oficial, por outro lado, encontramos um mesmo sistema de escrita alfabética, valendo-se de gêneros que nos são conhecidos, porém com rasgos diferenciados em decorrência de elementos sui generis do contexto, ou da situação de produção, ou das necessidades específicas dos participantes. A carta de amor, por exemplo, era um gênero que, segundo Sasso e Schram (2017), "ao longo de séculos, nos conectou ao lado profundamente humano de um coração apaixonado, burilada a mão, uma alma falando com outra" ${ }^{\text {. Hoje, no }}$ entanto, num contexto em que essa prática é obsoleta, portanto, quase desconhecida, e onde a insegurança determina a relação de muitos com a língua escrita (devido à falta de domínio da ortografia, à escolaridade baixa), uma nova prática emerge, não sancionada pela elite letrada, mas adotada por muitos: o modelo digital de carta de amor, já pronto para ser usado, como um site divulga "Procurando cartas de amor? Aqui você encontra as melhores Cartas de Amor para demonstrar todo seu amor"6 ou justificando a existência do serviço pela dificuldade que a escrita representa: "Declarar seus sentimentos para quem você ama pode não ser uma tarefa fácil, por isso separamos para

\footnotetext{
5 "....all [love letters] that have been written throughout the centuries, connect us to the deeply human side of a loving heart engraved by hand. It is an honor to hear one soul speaking to another."

${ }^{6}$ https://www.belasmensagensdeamor.com.br/cartas/
} 
você lindas cartas de amor para transformar em palavras tudo o que preenche o seu coração" 7 .

Há, no entanto, letramentos vernáculos que fazem muito mais do que preservar a face daqueles que se sentem inseguros em relação ao uso da língua escrita, e deles se ocupam vários artigos sobre o assunto neste número da revista. Os modos vernáculos de apropriação de gêneros estáveis, convencionados, porém transformados e postos a serviço de necessidades comunicativas, ou de sobrevivência, ou como manifestações de resistência em comunidades periféricas, discriminadas, vulnerabilizadas, nas quais habitam pessoas que procuram tornar-se protagonistas de sua história, estão amplamente representados: por exemplo, na formação do bloco carnavalesco Afoxé Filhos de Zaze, da cidade de Juazeiro (BA), que compõe letras para denunciar a intolerância contra os terreiros e outras formas de diversidade cultural. Estão também representados nas vozes femininas do Clã Virá, cujas performances "entre as margens" do rio São Francisco servem de palco para seus poemas de denúncia do sistema patriarcal que continua sendo reproduzido desde a chegada dos portugueses. A luta por espaço e reconhecimento faz parte, ainda, dos recitais públicos de cordel do grupo Ser Tão Poeta, que até subverte as funções de espaços dedicados ao consumo no seu afã de chegar a um público grande e diversificado com o fim de resgatar e valorizar a cultura popular nordestina.

É de grande mérito dos novos pesquisadores, ainda em processo de formação, e de seus orientadores, o tratamento de tais práticas cênicas como práticas de letramento. De fato, trata-se de letramentos de resistência, se não de reexistência ${ }^{8}$, que procuram renovar as relações hierárquicas entre grupos sociais, por meio da reafirmação dos saberes do grupo periférico para fins de autovalorização e de subversão dos papéis e lugares que lhe são atribuídos pelos grupos mais poderosos. Essas práticas, quando circulam no espaço escolar ou no espaço acadêmico, são tratadas, em geral, como exemplos do tradicional (em oposição ao moderno e contemporâneo); do regional (em

\footnotetext{
${ }^{7}$ https://www.mensagenscomamor.com/lindas-cartas-de-amor

${ }^{8}$ O conceito de reexistência é de Walsh (2008); Garcia (2012). Letramentos de reexistência foi o termo utilizado por Souza (2011) para descrever as práticas de letramento (leitura, composição musical, debate), de jovens integrantes do movimento hip-hop na cidade de São Paulo.
} 
oposição ao nacional); do exótico (em oposição ao normal); do folclórico (em oposição ao erudito) ${ }^{9}$.

Quando consideradas juntamente com propostas de letramento escolar inovadoras, como acontece neste conjunto de textos, as práticas adquirem novos significados, dentre os quais sua análise e apreciação como multiletramentos ${ }^{10}$ : primeiro, porque são constituídas na e pela diversidade de sistemas semióticos e de modalidades de comunicação que entram em contato na sua construção e mobilização e, segundo, porque usam variedades linguísticas, registros e gêneros diversos para contar experiências, sofrimentos, alegrias, para denunciar, mesmo que não tenham a legitimidade da escrita balizada pela norma culta ou pelo cânone literário.

Nessa linha de pensamento, as práticas emergentes de uso da escrita - leitura de estatuto, registro de eventos em atas, elaboração de requerimentos - das idosas que fundaram uma Associação de Mulheres Rurais em Saquinho e região, ensaiadas e mobilizadas para poder lidar com instituições burocráticas, também podem ser caracterizadas como multiletramentos quando são consideradas tanto sua base intercultural quanto sua multimodalidade nos esforços de comunicação dessas senhoras com grupos dos quais diferem quanto aos seus letramentos. São práticas que se sustentam não apenas nos modelos padronizados do gênero fornecidos pelas instituições de poder, mas também nas práticas cotidianas do grupo de mulheres, tanto orais como escritas.

Adentrando no letramento escolar na busca de elementos para elaborar uma pedagogia intercultural que tem o conflito como pressuposto, várias frentes podem ser pensadas: a questão da identidade de gênero é uma delas. Uma pedagogia intercultural envolve a flexibilização de diretrizes de ensino preocupadas não apenas com competências a serem atingidas pelo alunado, mas com a diversidade e o multiculturalismo, posto que a escola é um lugar de encontro de alunos com diversas orientações sexuais e identidades de gênero, o que faz do corpo um território de

\footnotetext{
${ }^{9}$ Para Boaventura Souza Santos (2009) essas distinções são próprias do pensamento por ele denominado pensamento abissal, o paradigma científico dominante, extremamente excludente, que está baseado em distinções como conhecimento local e conhecimento global, conhecimento científico e sentido comum. Segundo o autor, essas e outras dicotomias semelhantes suprimiriam e relegariam ao esquecimento experiências e saberes alternativos, como as epistemologias do sul e a partir do sul.

10 Tal como proposto por Kleiman e Sito (2016) para caracterizar letramentos de quilombolas em interações interculturais com funcionários do governo brasileiro durante processos de regularização de terras.
} 
permanente conflito. Uma proposta de problematização dos contextos de deslocamento, como a apresentada na Pedagogia queer/cuir/cu, pode vir a ressignificar criticamente conceitos de diversidade e multiculturalidade, não apenas como aceitação ou tolerância do diferente, mas como exploração do "impensado, do ambíguo", da incerteza, como questionamento e problematização do diferente: "as possibilidades de perturbação, transgressão e subversão das identidades existentes" (URZÊDA FREITAS, 2018, p. 143). Assim agindo, o diferente poderá, talvez, sair do isolamento no qual o 'normal' ou 'normativo' (neste caso, o heteronormativo) o mantém, uma vez que todos somos responsáveis pelos (micro)contextos que produzimos, reproduzimos ou impomos por meio do discurso.

Situados também no campo escolar, encontramos dois textos sobre leitura, com propostas alternativas de letramento escolar. Uma delas aborda uma prática de leitura para a formação do alfabetizador, denominada "leitura deleite" pelos formadores do Programa de Alfabetização na Idade Certa (PNAIC). Baseada na ideia do professor como modelo de leitor, a leitura deleite envolve a sensibilização dos alfabetizadores para aspectos de fruição e apreciação estética de textos selecionados segundo critérios de ordem pessoal e de qualidade textual. Não há como negar a relevância desta prática se partirmos do pressuposto de que é vergonhoso ensinar uma criança a apropriar-se do sistema de escrita alfabética apenas por meio da decodificação de palavras e frases sem contexto, sem lhe ensinar também a amar os livros. Trata-se de uma estratégia de letramento muito necessária neste momento em que o Ministério de Educação, revivendo uma antiga e já 'cientificamente' superada polêmica ${ }^{11}$, impõe o método fônico como único método de alfabetização do país no caderno Política Nacional de Alfabetização.

\footnotetext{
${ }^{11}$ A polêmica está há longo superada entre os pesquisadores que se dedicam seriamente ao estudo da alfabetização. Há 20 anos, por exemplo, a Associação Internacional da Leitura (1999) publicou uma declaração de princípios sobre os métodos que afirmava que "não existe um método único, ou combinação única de métodos que possa ensinar a ler a todas as crianças com sucesso". E adicionava que era por essa razão que "os professores devem desenvolver um profundo conhecimento de múltiplos métodos para ensinar a ler e um profundo conhecimento das crianças sob seu cuidado, para que possam criar o equilíbrio apropriado dos métodos requeridos pelas crianças a quem ensinam" (de fato, uma recomendação que beneficiaria muito mais a atuação dos políticos que a dos professores, que já sabem isso). Entretanto, as recentes políticas educacionais consideram que o letramento e o construtivismo são teorias políticas e ideológicas (no sentido negativo já discutido), e com base nisso, reascenderam a velha polêmica sobre a supremacia de um método de alfabetização sobre outro. O método escolhido, desta vez, é o fônico que, como todo método relacionado ao princípio alfabético, funciona para ensinar algumas coisas, mas não outras, no complexo processo de aquisição da língua escrita. É muito triste, para pesquisadores sérios, ver questões técnicas, sobre assuntos vitais para as crianças do Brasil, sendo contaminadas por ideologias políticas.
} 
A ressignificação de diversas atividades e práticas de leitura pode também vir a ser o resultado de assumir a leitura como prática social de alcance político. Essa é a assunção básica de toda atividade de leitura (assim como de produção de escrita e de oralidade) que é parte integrante de projetos de letramento que visam ao exercício da cidadania e agência cívica do aluno. Nas oficinas de um projeto, como a oficina de leitura discutida neste volume (parte integrante de um projeto de letramento sobre desarmamento), está implicado o respeito à autonomia e à identidade do estudante, garantindo seu direito de opinar, decidir coletivamente e deliberar sobre as atividades e ações a serem realizadas colaborativamente no projeto. Nessa ressignificação das atividades de leitura, o letramento escolar adquire novos sentidos, entre eles a compreensão dos fatos sociais e da realidade, permitindo ao aluno posicionar-se no mundo local da escola e no mundo social mais amplo. Tudo isso acontece num processo que só pode ser entendido como uma dinamização dos gêneros discursivos que transforma a leitura naquilo que lhe é constitutivo fora do ambiente escolar: uma experiência significativa para a produção de sentidos situados e críticos para a prática efetiva de transformação da realidade.

Toda atividade de leitura enfatiza hoje a importância do acesso e da disponibilidade de diversos recursos e mídias digitais. A exploração de letramentos digitais focados na Pedagogia de Multiletramentos do chamado Grupo de Londres congrega um conjunto de pesquisadores da educação, antropologia, estudos da linguagem ${ }^{12}$ voltados para o estudo dos letramentos, que visam tornar a escola mais inclusiva quanto à diversidade linguística, comunicativa e tecnológica e que, como a $\mathrm{UNESCO}^{13}$, acredita nas potenciais contribuições das Tecnologias da Informação e da Comunicação para a equidade, o acesso universal à educação, o desenvolvimento de programas de ensino e de formação docente de qualidade e, inclusive, para governança e administração mais eficiente dos programas educacionais. Se apenas uma dessas crenças for partilhada, faz pleno sentido aceitar o desafio de tornar acessível um material de qualidade para a inclusão de todos os alunos nas mídias digitais, por meio, por exemplo, do ensino de novos gêneros digitais, como o meme, também tematizado

\footnotetext{
${ }^{12}$ Eles são: Courtney Cazden, James Gee e Sarah Michaels, dos EUA; Bill Cope, Mary Kalantzis, Allan Luke, Carmen Luke e Martin Nakata, da Australia; Norman Fairclough e Gunther Kress da Inglaterra.

${ }^{13}$ ICT in Education. https://en.unesco.org/themes/ict-education
} 
neste número: um texto de grande atualidade, intertextual e interdiscursivo, altamente compreensível, com grande valor e potencial didático para o ensino da leitura crítica.

O amor pela leitura nasce do contato com bons livros em situações que transmitem segurança, aconchego, enfim, situações em que impera a afetividade ${ }^{14}$. Daí a importância de agências e agentes de letramento, como bibliotecas e bibliotecários, que promovam um ambiente de letramento que, na nossa definição, necessariamente implica um ambiente de uso da escrita marcado por emoções positivas nas relações entre usuários e bibliotecários. A cuidadosa apresentação metodológica para realizar um exame detalhado do ambiente, das percepções dos sujeitos e da qualidade das práticas letradas desenvolvidas em bibliotecas escolares em regiões afastadas de grandes centros é uma contribuição importante para este volume, vinda de um pesquisador em formação para avaliar o papel da biblioteca no letramento do alunado do semiárido brasileiro. Além disso, o artigo apresenta um roteiro metodológico que poderá orientar futuros estudos sobre as bibliotecas em diferentes contextos de letramento escolar.

A função da escola é inserir o aluno no mundo da leitura e da escrita, algo que não é atingido quando o ensino se reduz à reprodução de atividades mecânicas de decodificação, desconsiderando as práticas sociais nas quais os sujeitos lidam - ou podem vir a lidar - com leitura e escrita para agir no mundo. Daí a relevância das pesquisas apresentadas neste volume, em contextos variados nos quais emergem práticas letradas locais e globais que podem expandir as formas de atuação da escola e torná-las mais significativas. Práticas como o debate, ou como a leitura em voz alta, adotadas tanto pela escola para desenvolver no aluno a capacidade crítica, como por comunidades de escritores periféricos para resgatar formas literárias regionais populares, também periféricas, ou práticas de escrita colaborativa para participar em projetos escolares, ou para compor letras e músicas de resistência à intolerância e ao preconceito, ou para fazer frente às exigências de letramento do mundo burocrático para ter a mera existência reconhecida, têm potencial pedagógico e objetivos comuns: conscientizar-nos de que outras realidades são possíveis e que são diversas e múltiplas práticas de letramento as que nos aproximam desse novo mundo.

\footnotetext{
${ }^{14}$ Assim como Vigotski (2001), para quem a afetividade é parte ativa do processo de aprendizagem, consideramos a afetividade essencial no processo de letramento.
} 


\section{Referências bibliográficas}

GARCÍA, A. Espacialidades del destierro y la re-existencia: afrodescendientes desterrados en Medellín, Colombia. Medellín: La Carreta Editores, Instituto de Estudios Regionales (INER), Universidad de Antioquia, 2012.

INTERNATIONAL READING ASSOCIATION. Using Multiple Methods of Beginning Reading Instruction. A Position Statement of the International Reading Association. Newark, DE: International Reading Association, 1999. https://eric.ed.gov/?id=ED435085

KLEIMAN, Angela B.; SITO, Luanda. "Multiletramentos, interdições e marginalidades". IN: KLEIMAN, Angela. B.; ASSIS, Juliana Alves. (Orgs.). Significados e ressignificações do letramento. Desdobramentos de uma perspectiva sociocultural da escrita. Campinas: Mercado de Letras, 2016, p. 169-198.

SANTOS, B. S. (2009). Una epistemología del sur: la reinvención del conocimiento y la emancipación social. México: Siglo XXI, CLACSO.

SASSO, Sandy Eisenberg; SCHRAM, Peninnah. Love letters: a lost writing genre. Hadassah Magazine, fevereiro 2017. https://www.hadassahmagazine.org/2017/02/10/love-in-letters/

SOUZA, A. L. S. Letramentos de reexistência: poesia, grafite, música, dança: HIP. São Paulo: Parábola Editorial, 2011.

STREET, B.V. Literacy in theory and practice. Cambridge: Cambridge University Press, 1984.

URZÊDA FREITAS, Marco Túlio. Letramentos queer na formação de professorxs de línguas: complicando e subvertendo identidades no fazer docente. Tese de doutorado. Goiânia, UFGO, 2018.

VIGOTSKI, L. S. Psicologia Pedagógica. São Paulo: Martins Fontes, 2001.

WALSH, C. Interculturalidade Crítica e Pedagogia Decolonial: in-surgir, re-existir e reviver. In: CANDAU, V.M. (org.). Educação Intercultural na América Latina: entre concepções, tensões e propostas. Rio de Janeiro: Editora 7 Letras, 2009, p. 12-42. 